\title{
MANAJEMEN STRESS CALON LEGISLATIF PASCA PEMILIHAN UMUM LEGISLATIF TAHUN 2014 (Studi Kasus Pada Calon Legislatif Gagal)
}

\author{
Oleh : \\ YUNI INDAH \\ Dosen Prodi Administrasi Negara FISIP Universitas Ratu Samban Bengkulu Utara
}

\begin{abstract}
This study aimed to analyze the sources of stress, resilience indicators of individual candidates in facing stress, the level of stress and techniques to manage stress when candidates failed to gain political stance. The results showed that the source of stress was the political funds issued exceed the financial capacity of the contestants. Source of political funds obtained from the loan was not able to increase their electability because in addition to economic investment, political and social investment was also required. During the post-electoral, contestants who failed underwent stress of mild category to severe stress category. For mild stress contestants only perform a cooling-off was accompanied by a family. While for contestants who were severely depressed, they should be treated in a mental hospital. From the results of this study, it's recommended the need for the role of political parties in dealing with contestants' stress. The Government must be present in the stress of candidate problems in terms of policy, namely the duty of political parties and governments to facilitate recovery and mental health. Before the fight, the political parties should provide psychological education for mental preparedness to face the worst.
\end{abstract}

\section{Keywords: Stress Management, Candidates, Legislative Election}

\section{PENDAHULUAN}

Tanggal 9 April 2014 dilaksanakan agenda demokrasi setiap lima tahunan artinya pesta demokrasi, pemilihan calon legislatif. Pesta demokrasi ini selalu meriah dan ditambah dengan bertebaran gambar-gambar calon legislatif di berbagai sudut kota. Calon legislatif mulai rajin mendatangi berbagai kegiatan masyarakat mulai dari acara non formal sampai pada acara formal dengan tujuan agar lebih dikenal oleh masyarakat dan berharap agar dapat dipilih. Suhu politik semakin meningkat dengan adanya kompetisi dalam memperebutkan suara rakyat.

Menurut data KPU pusat, ada tiga tingkatan pemilu legislatif yaitu DPR RI, DPRD Provinsi, DPRD Kabupaten/Kota dan Dewan Perwakilan Daerah (DPD). Secara rinci, jumlah daerah pemilih di tingkat pusat DPR RI sebanyak 77 dapil dengan 560 kursi. DPD terdiri dari 33 dapil dengan jumlah kursi yang diperebutkan 132 kursi. DPRD provinsi ada 259 dapil dengan 2.112 kursi. Lalu terbanyak adalah DPRD Kabupaten/Kota 2.102 dapil dengan 16.895 kursi. Secara total jumlah calon legislatif (secara nasional) lebih kurang 200 ribu orang.

Data KPU Provinsi Bengkulu menyebutkan bahwa terdapat 2.500 caleg yang akan memperebutkan kursi pada tanggal 9 April. Kuota atau kursi yang akan diperebutkan itu hanya sebanyak 328 kursi. Terdiri dari kursi DPD RI 4 kursi, DPR RI 4 kursi, DPRD Provinsi 45 kursi dan DPD Kabupaten/Kota sebanyak 275 kursi (selengkapnya lihat grafis). Untuk DPRD Kabupaten/Kota ini paling sedikit 
tersedia 25 kursi dan paling banyak 35 kursi yakni untuk DPRD Kota Bengkulu.

Minimnya jumlah kursi yang diperebutkan dan jumlah caleg yang ikut berkompetisi membuat praktik money politic semakin marak. Sistem penentuan caleg terpilih tidak berdasarkan nomor urut, melainkan berdasarkan suara terbanyak yang diperoleh masing-masing calon legislatif dalam parpol peserta Pemilu. Fakta di lapangan menunjukkan bahwa untuk maju sebagai calon legislatif membutuhkan dana yang besar untuk menjaring suara rakyat. Untuk menjaring suara rakyat perlu dilakukan jauh hari sebelum masa kampanye tiba. Calon legislatif mengeluarkan dana yang besar dan tak terkontrol untuk membiayai kegiatan politiknya. Sehingga bagi calon legislatif yang kalah banyak mengeluarkan uang, tidak siap menghadapi kenyataan pahit bahwa mereka kalah dalam Pemilu. Kondisi membuat potensi stress pemilu 2014 semakin meningkat dari pemilu tahun 2009.

Sesuai ketentuan dalam Pasal 5 ayat 1 Undang Undang Pemilu Nomor 8 Tahun 2012 yang mengatakan bahwa Pemilu menganut sistem proporsional terbuka untuk kampanye, hampir seluruh biaya kampanye dibebankan pada caleg yang maju. Hal membuat potensi calon legislator untuk stres lebih besar pada Pemilu Legislatif 2014. Partai tidak ikut campur dalam hal pendanaan, caleg yang modalnya besar bisa mengeluarkan dana besar tanpa kontrol.

Tidak sedikit caleg yang mengalami stress dilarikan ke rumah sakit. Hal ini bukan sebuah fenomena aneh dalam setiap Pemilu. Menurut Menteri Sosial Salim Segaf Al-Jufri, diperkirakan pada pemilu 2014 jumlah caleg stres bakal meningkat dari musim kampanye tahun lalu, khusus bagi caleg yang kalah. Maka dari itu Mensos menghimbau seluruh daerah khususnya rumah sakit agar menyediakan tempat ekstra untuk perawatan calon anggota legislatif (caleg) yang kalah dalam Pemilihan Legislatif 2014 ini.

Dari fenomena ini peneliti tertarik untuk mengakaji bagaimana caleg mengelola stress dalam menghadapi kekalahan dalam pemilu. Jika fenomena caleg stress ini dibiarkan tanpa ada penanggulan akan menambah masalah sosial di negara kita. Dari fenomena ini perlu diadakan penelitian lebih lanjut mengenai bagaimana para caleg mengelola stress yang mereka alami.

\section{METODE PENELITIAN}

Penelitian ini menggunakan desain deskripsi kualitatif naturalistik studi kasus. Penelitian dilakukan di Kabupaten Bengkulu Utara. Informan dalam penelitian ini adalah calon anggota dewan legislatif yang gagal dan sukses dalam pemilihan legislatif tahun 2014 dan ahli psikologi. Metode Pengumpulan Data adalah dengan metode observasi, wawancara mendalam, pustaka dan penelusuran online.

Teknik analisis yang digunakan dalam penelitian ini adalah analisis deskriptif kualitatif dengan mengikuti langkah analisis Interactive Model. Untuk mengecek keabsahan data, peneliti menggunakan teknik triangulasi data.

\section{PEMBAHASAN}

Dalam Pemilu legislatif menganut prinsip Multi Member Constituency (Sistem Proporsional Terbuka/sistem Perwakilan Berimbang) artinya dalam Pemilu ada kebebasan bagi pemilih dalam menentukan kandidat yang didukungnya. Pada Pemilu 2009, dilaksanakan.

Berpedoman kepada UU No. 10 Tahun 2008 Tentang Pemilihan Umum Anggota DPR, DPD, DPRD Provinsi dan DPRD Kabupaten/Kota, dalam UndangUndang ini menyebutkan bahwa untuk Pemilu 2009 menganut Sistem Proporsional terbuka. Hal ini terlihat dari adanya penerapan aturan "nomor urut", dimana calon yang memperoleh suara terbanyak di dalam suatu partai tidak otomatis terpilih menjadi wakil. Aturan ini 
kemudian diuji dan diputuskan oleh Mahkamah Konstitusi (MK) melalui Judicial Review terhadap UU No. 10 Tahun 2008, keputusan MK mengabulkan dan memutuskan sistem suara terbanyak sebagai patokan untuk mengalokasikan kursi kepada partai-partai yang memperoleh kursi

\section{Sumber Stres Caleg}

Menjadi anggota legislatif merupakan harapan bagi semua calon yang bertarung dalam pemilihan umum legislatif. Semua calon menargetkan menang dalam pemilu. Semua anggota berjuang mengerahkan semua sumber daya yang dimiliki untuk memaksimalkan perolehan suara dalam pemilu legislatif.

Menjelang pilkada, biasanya bermunculan calon-calon yang langsung mengusung karakter keempat. Mengandalkan kapitalisme demi mencapai tujuan politiknya. Hal ini sebenarnya tidak mengherankan, sebab kecenderungan industri politik dalam pasar demokrasi di Indonesia selalu berpihak kepada individu atau kelompok yang memiliki modal besar. Sementara calon yang memiliki modal kecil akan mendulang suara yang sedikit. Hal ini diungkapkan oleh informan NS. NS menghasiskan dana Rp 50.000.000,-. Dana yang terbilang kecil jika dibandingkan dengan kandidat yang lain. Kekalahan inilah yang menimbulkan kekecewaan yang mengakibatkan stress. Berdasarkan wawancara, Sabtu , 5 Maret 2015, mengatakan:

"benar-benar saya kecewa, dan sakit hati karena masyarakat yang juga temasuk keluarga kita tidak mendukung kita. Mereka hanya manis di bibir namun pada akhirnya mereka memilih karena amplop. Saya hanya mendapatkan suara 412"

Perasaan kecewa juga dirasakan oleh FZ dari dapil 4. Dalam wawancara yang dilakukan Senin, 7 Maret 2015, FZ mengatakan bahwa:

"Ya sangat kecewa. Jadi yang saya lakukan membantu masyarakat baik membantu secara individu dan kelompok, berkarya di program PNPM, mengenal baik dan dekat dengan masyarakat, semua itu tidak ada artinya buat masyarakat. Yang merepa pilih adalah yang memberikan amplop pada mereka."

Dari kedua informan tersebut dapat disimpulkan bahwa mereka mengalami kekecewaan yang berat karena hasil Pemilu tidak sesuai dengan harapan mereka. Harapan kadang tidak sesuai dengan fakta yang ada, hal inilah yang menjadi sumber stress. Kegagalan dalam pemilu memicu kekecewaan atau stress atau bisa kita sebut dengan frustasi. Kondisi ini digambarkan oleh Robbin yang mengatakan bahwa stress merupakan kondisi dinamik dalam individu menghadapi peluang, kendala atau tuntutan yang terkait dengan apa yang sangat diinginkannya dan yang dihasilkan dipersepsikan sebagai tidak pasti tetapi penting (Robbin, 2006: 739).

Dari hasi penelitian diperoleh beberapa faktor kegagalan caleg dalam pemilu legislatif tahun 2014 di Kabupaten Bengkulu Utara adalah:

a. Dana Politik

Untuk dapat rajin menyapa calon pemilih diperlukan modal atau biaya tambahan. Bukan tidak mungkin angkanya semakin membengkak. Sekurang-kurangnya biaya untuk transportasi, telekomunikasi dan akomodasi. Ada biaya tak terduga. Dana politik yang menyangkut komunikasi misalnya membeli pulsa, sedangkan akomodasi meliputi sewa posko, internet (membuat situs/website/jejaring sosial dunia maya), iklan (televisi, radio, media cetak/elektronik/dunia maya), honor tim 
sukses, perizinan-pajak, konsumsi, atribut pemilu

Data yang diperoleh dari calon legislatif yang memenangkan Pemilu 2014 menyebutkan bahwa untuk mendulang suara di seluruh TPS AL mengeluarkan dana $\mathrm{Rp}$ 500.000.000,-. NS informan dalam penelitian ini mengatakan bahwa dirinya telah mengeluakan $\mathrm{Rp}$ 50.000.000,- dana politik dihari pemilihan. Dirinya mengatakan bahwa dirinya kecewa dan sress dengan hasil pemilu 2014. Menurut NS untuk mencalonkan diri sebagai anggota dewan selain dibutuhkan uang, popularitas dan nomor urut.

Informan FZ mengatakan bahwa dirinya menghabiskan dana $\mathrm{Rp}$. 280.000.000,- namun masih juga gagal. Informan $\mathrm{ZN}$ menghabiskan dana $\mathrm{Rp}$. 600.000.000,- juga belum berhasil. Berikut disajikan data dana politik yang dihabiskan dalam pemilu legilatif 2014 dan sumber dana

Tabel

Dana Politik dan Sumber Dana perdagangan sudah cukup untuk digunakan dalam memulai sebuah usaha.

Pentingnya peranan dana politik ini diungkapkan oleh FZ. FZ mengatakan:

“ mustahil berjuang tanpa uang. Jadi orang yang mau nyalon memang harus siap uang yang banyak, untuk mendulang suara"

Berkaitan dengan cost politik ini merujuk pada penelitian dari FK Institut sebuah lembaga yang dibentuk kalangan aktivis muda di Tapanuli Selatan dan Padang Sidempuan - berpendapat, dengan system demokrasi suara terbanyak saat ini membuat cost politik yang dikeluarkan seorang caleg untuk terpilih dinilai sangat luar biasa besar dan sudah tidak masuk akal lagi. temuan Pusat Studi Sosial Politik Indonesia (Puspol Indonesia) bahwa para caleg DPR RI yang ada di Jakarta mengeluarkan biaya antara Rp.200 juta sampai Rp. 1,5 miliar. Angka yang tentu saja jika digunakan untuk bisnis di sektor perdagangan sudah cukup untuk digunakan dalam memulai sebuah usaha.

\begin{tabular}{|l|l|l|l|}
\hline No & Nama Informan & Jumlah dana politik & Sumber dana \\
\hline 1 & NS & $\operatorname{Rp} 50.000 .000,-$ & Tabungan \\
\hline 2 & FZ & $\operatorname{Rp} 280.000 .000,-$ & Hasil kerja proyek \\
\hline 3. & ZN & $\operatorname{Rp} 600.000 .000,-$ & Pinjaman dari pengusaha \\
\hline 4. & AR & $\operatorname{Rp} 200.000 .000,-$ & Pinjaman dari pengusaha \\
\hline 5. & TK & $\operatorname{Rp~} 150.000 .000,-$ & Pinjaman \\
\hline
\end{tabular}

Sumber Data Primer terolah: Informan, 5 Januari 2016

Dari tabel di atas terlihat bahwa yang dana politik terendah adalah $\mathrm{Rp}$ 50.000.000 dan dana politik terbesar adalah Rp 600.000.000,- yang dikeluarkan oleh ZN. ZN adalah calon legislatif yang gagal dalam pemilu 2014 yang sempat dirawat di Rumah Sakit Jiwa.

Jika kita bandingkan dengan daerah lain seperti Jakarta, berdasarkan temuan Pusat Studi Sosial Politik Indonesia (Puspol Indonesia) bahwa para caleg DPR RI yang ada di Jakarta mengeluarkan biaya antara Rp. 200 juta sampai Rp1,5 miliar. Angka yang tentu saja jika digunakan untuk bisnis di sektor b. Kurangnya Popularitas di Masyarakat Dalam dunia politik popularitas seseorang juga bisa dirancang atau direkayasa atau bahkan 'dibeli' dengan sejumlah uang. Tidak sedikit orang ingin populer dengan melakukan berbagai cara. Agar populer setiap caleg harus mampu membangun Personal Brand. Personal branding menjadi begitu penting untuk dikerjakan agar caleg menjadi dikenal oleh target audience di masing-masing dapil.

Setiap caleg harus mampu membangun Personal Brand. Personal branding menjadi begitu penting untuk dikerjakan agar caleg menjadi dikenal oleh target audience di masing-masing dapil. 
Faktor kurangnya popularitas inilah yang dirasakan oleh informan NS sehingga dirinya kalah dalam pertarungan. Dikatanyannya:

"jadi penentu dalam pemilu bukan

Cuma uang tapi juga popularitas.

Ini baru pertama kali saya mencalonkan diri. Mungkin belum banyak yang saya perbuat untuk masyarakat sehingga saya begitu belum dikenal."

Pendapat yang berbeda diungkapkan oleh FZ, FZ mengatakan bahwa:

"Saya sudah cukup populer. Saya mencalonkan diri karena dukungan masyarakat namun apa mereka hanya memilih pada orang yang memberikan uang pada mereka. Mereka tidak berfikir apakah calon itu mereka kenal atau tidak, ",

Dari pendapat FZ dapat diketahui bahwa popularitas tidak menjadi elektabilitas calon. Dari kedua pendapat di atas dapat disimpulkan bahwa popularitas bukan satu-satunya penentu kemenangan kandidat. Ada hal lain yang penting adalah dana politik. Popularitas dirancang untuk menarik minat konstituen dan harus didukung oleh finansial guna mendukung political marketing. Dikutip Firmanzah (2008) political marketing adalah sebuah konsep yang menawarkan bagaimana sebuah parpol atau seorang kandidat dapat membuat program yang berhubungan dengan permasalahan aktual. Di samping itu, marketing politik merupakan sebuah teknik untuk memelihara hubungan dua arah dengan pubik. Secara sederhana marketing politik berarti aplikasi kegiatan marketing di dalam ruang politik yang umumnya terkonsentrasi pada saat Pemilu atau Pilkada.

Kelima informan kurang bisa memelihara hubungan baik dengan pemilih. Pasca kekalahan para informan enggan untuk berkomunikasi lebih lanjut dengan informan.

\section{Ketahanan Stres Calon Legislatif}

Fenomena caleg stres karena kegagalan pemilu dan akhirnya masuk rumah sakit jiwa dialami oleh informan ZN yang menghabiskan dana 600 juta rupiah. Sumber dana berasal dari pinjaman pengusaha. Informan sudah menginvestasikan waktu, energi, dan uang dalam jumlah banyak, tapi semua itu tidak membuahkan hal. Harapan tinggi membuat mereka depresi berat.

Sementara informan yang lain juga mengalami stress namun tidak sampai dirawat di rumah sakit jiwa. NS mengatakan bahwa dirinya memang stres tapi masih bisa saya kendalikan tidak sampai jatuh sakit atau masuk rumah sakit jiwa.

Pendapat FZ hampir sama dengan NS. FZ mengatakan:

"meski saya menghabiskan uang yang banyak tapi saya tidak sampai sakit. Kesal, kecewa tentu ada. Uang kan bisa dicari”.

Sumber dana politik kedua informan tersebut bukan dari meminjam tapi dari tabungan mereka. Menurut FZ:

"saya bekerja sebagai kontraktor, tiap ada hasil dari pekerjaan itu saya sisikan dana selama bertahun-tahun,"

Kondisi ketiga informan dalam menghadapi stres sangat berbeda. Menurut Robbin (2006: 798-790) mengemukakan bahwa perbedaan individu dapat menentukan tingkat stress yang ada. Kondisi ini dijelaskan oleh dosen psikologi Universitas Indonesia, Ratna Juwita. Ratna Juwita mengatakan bahwa sebenarnya setiap orang punya ketahanan fisik dan psikis yang berbedabeda. Nah, bagi mereka yang ketahanan psikisnya lemah rentan mengalami depresi. Menanggapi fenomena caleg yang sempat dirawat di rumah sakit jiwa Ratna mengatakan: 
"Kemungkinan caleg depresi ini mempunyai ketahanan psikis yang lemah."

Selanjutnya Ratna juga mengatakan bahwa jika salah satu anggota keluarga Anda mengalami kegagalan ini, sebaiknya jangan diabaikan. Menurut Ratna, tidak hanya sakit psikis, hal ini juga bisa berdampak pada kesehatan fisik. Dikatakannya:

"Karena tingkat adrenalin mereka yang tinggi dapat menyebabkan serangan jantung,"

Perbedaan individu dalam menghadapi berbeda-beda. Menurut Robbin dapat dilihat dari beberapa indikator

1. Pengalaman kerja, informan NS telah berberkecimpung di dalam partai politik sejak tahun 1999. Sedangkan informan FZ meski berkesimpung dipartai politik baru tahun 2010, namun pengalaman organisasi di dalam masyarakat seperti dalam program PNPM telah dimulai program ini dimulai. Wahjono mengemukakan bahwa pengalaman pada pekerjaan cendrung berhubungan secara negatif dengan stres, karena pengalaman akan mengajarkan oranguntuk mengembangkan mekanisme mengatasi stres (Wahjono, 2010: 112)

2. Dukungan sosial, menurut Wahjono berkaitan degan hubungan kolegial rekan dan keluarga. Kedua informan FZ dan NS memiliki keluarga yang sangat mendukung dirinya dalam berbagai kegiatam.

3. Ruang (locus) ruang kendali. Orang yang memiliki kendali internal yakin bahwa mereka akan mengendalikan tujuan akhir lebih tahan pada stress. Kedua informan FZ dan NS tidak putus asa dengan kegagalan bahkan keduanya tetap semangat untuk mencalonkan diri kembali

4. Keefektifan diri merujuk pada keyakinan individu bahwa dirinya memiliki kemampuan. Kedua informan optimis bahwa kemenangan akan mereka raih pada Pemilu yang akan datang.

5. Tingkat kepribadian orang dalam mensikapi permusuhan dan kemarahan. Orang yang memiliki tingkat permusuhan dan kemarahan yang tinggi cendrung mencurigai dan tidak mempercayai orang lain. Hal ini terlihat bahwa kedua informan masih berpikir positif pada konstituen yang tidak memilih mereka.

\section{Teknik Pengolahan Stres Calon Legislatif}

Manajemen stress adalah sebuah kecakapan dalam menghadapi tantangan dengan cara mengendalikan tanggapan (respon) secara proporsional dengan demikian manusia bisa memperbaiki kualitas hidupnya. Ada reaksi yang beragam dari informan setelah mengetahui bahwa mereka gagal dalam pemilu Legislatuf 2014. Informan FZ mengatakan:

"Setelah saya tahu gagal saya ajak istri saya ke kebun, ambil parang, menebas ladang 2 hektar untuk dibuat kebun. Saya kesal ternyata apa yang saya buat selama ini tidak ada artinya. Namun kemudian saya meyadari bahwa saya masih punya waktu untuk mencalon lagi. Istri saya menguatkan dan terus memberi semangat,"

Hal yang sama juga dirasakan NS:

"setelah mengetahui saya kalah, saya ajak teman saya yang juga kalah ke pantai. Di sana saya menjerit sekencang-kencangnya. Saya menangis bersama dengan teman saya itu. Keluarga saya terutama istri mencoba membuat saya kuat dan menghadapi keadaan ini bersama-sama."

Dari pendapat kedua informan tersebut dapat kita lihat bahwa keluarga sangat berperan dalam mengatasi stress. 
Pentingnya peran keluarga ini dijelaskan oleh Ratna Juwita dengan mengatakan:

Jika keluarga Anda sudah mengalami kerugian besar, sebaiknya jangan dipersalahkan. Lebih baik menunggu emosinya membaik baru menyelesaikan masalah-masalah keluarga. Kenali gejala depresi berat, Jika dalam waktu tiga hari, ia menderita ganguan kejiwaan seperti stres, susah tidur dan tidak bernafsu makan, maka keluarga harus segera membawa ke klinik kejiwaan untuk mendapat perawatan agar tidak sampai menderita depresi yang lebih berat lagi, seperti ingin bunuh diri".

Teknik kedua informan di atas dengan cara penenangan pikiran serta teknik penenangan melalui aktivitas fisik. Manajemen stress ini erat kaitannya dengan istilah "Flight or Fight". Flight berarti menanggalkan kondisi yang menekan mental sedangkan Fight adalah melawan dengan baik kondisi tersebut. Opsi Fight ini yang kemudian bermuara pada manajemen stress.

Berbeda dengan kedua informan di atas, $\mathrm{ZN}$ dan TK mengalami depresi berat sehingga mereka tidak mengenali lingkungan mereka. Karena kondisi ini keluarga sepakat untuk merawat informan ke rumah sakit jiwa.

\section{PENUTUP}

\section{Kesimpulan}

Kesuksesan pemilu adalah harapan bagi semua calon legislatif yang bertarung di Pemilihan umum legislatif 2014. Tidak ada calon legislatif yang ingin kalah dalam pertarungan. Semua sumber daya yang dimiliki calon legislatif dimaksimalkan untuk memenangkan pemilu. Harapan yang besar untuk memenagkan pemilu membuat mereka berusaha bertarung sekuat tenaga. Sumber daya yang sudah dikeluarkan tidak seimbang dengan hasil, hal inilah yang membuat calon legislatif mengalami stress. Kegagalan dalam pemilu membuat calon legilatif kecewa.

Kegagalan calon legislatif dalam pemilu disebabkan oleh beberapa hal yaitu dana politik. Tidak bisa dipungkiri bahwa dalam kegiatan untuk mendulang suara tidak bisa tidak semua calon membutuhkan dana. Fakta dari penelitian ini mengatakan bahwa calon diharuskan memiliki investasi ekonomi yang memang cukup memadai sehingga jika pun harus kalah dalam pertarungan tidak menyebabkan stress berat yang mengharuskan dirawat di rumah sakit jiwa. Selain investasi ekonomi yang kuat, individu juga harus memiliki investasi sosial dan politik di masyarakat yang akan mendongkrak dimasyarakat.

popularitasnya

Selain kemampuan investasi yang disebutkan di atas seorang invivdu harus memiliki kemampuan dalam membina hubungan baik dengan kontituentnya secara berkelanjutan. Hubungan yang baik dengan konstituent memungkinkan individu untuk, menawarkan dan mempromosikan diriya dan parpol pengusung. Mempelajari permasalahan faktual yang dihadapi pemilih untuk membuat program yang pro pemilih.

Tingkat ketahanan stress tiap indvidu berbeda-beda tergantung. 3 informan memiliki tingkat ketahanan stres yang lebih baik dari 2 informan dalam penelitian ini. 3 orang informan meski mengalami kegagalan namun dapat mengelola stres sehingga tidak menyebabkan stres berat seperti yang dialami oleh 2 informan yang tidak lagi mengenali diri dan lingkungannya sehingga harus dirawat di rumah sakit jiwa Bengkulu.

Teknik mengelola stres calon legislatif yang gagal berbeda-beda namun keempat informan memilih untuk mengalihkan perhatian dengan melakukan aktivitas fisik. Dalam mengelola stress peran keluarga sangat diperlukan guna memulihan keadaan psikis. 
Saran

Dengan maraknya korban stress pasca Pemilu, pemerintah dan Parpol harus hadir dalam memulihkan kesehatan

\section{DAFTAR PUSTAKA}

Agoes, Achidiat. (2003). Teori dan Manajemen Stres. Malang: Taroda.

Arikunto, Suharsimi. (2006). Prosedur Penelitian. Jakarta: Rineka Cipta

Brecht, G.(2000). Mengenal dan Menanggulangi Stres. Jakarta: PT Prenhallindo Bustaman, (2000)

Bruce I. Newman, Handbook of Political Marketing (California: Sage Publication, 1999).

Mencegah dan Mengelola stres. Dibuka dari http://www.search. Yahoo.com.

Cooper, C. (1995). Stres management yang sukses dalam sepekan. Jakarta : Kesaint Blanc.

Hardjana, A.M. (1994). Stres Tanpa Distres. Yogyakarta: Kanisius Ilmi, B,(2003).

Ginting, Alfito, Deanova, 2009, Selebritis Mendadak Politisi, Yogyakarta, Arti Bumi Intara

Looker, T. (2005). Managing stress mengatasi stress secara mandiri. Surabaya: Penata Aksara psikis calon yang mengalami stress dan memerlukan perawatan medis dan non medis.

Maramis, W. F. 2006. Ilmu Perilaku dalam Pelayanan Kesehatan. Surabaya : Airlangga university press.

Musbikin, Iman. (2005). Kiat-kiat Sukses Melawan Stres. Surabaya : Jawara Nursalam,

Rivai Vithzel, Mulyadi Deddy, (2011), Kepemimpinan dan Perilaku Organisasi, Jakarta: Raja Grafindo Wahjono Imsm Sentor, (2010)Perilaku Organisasi, , Yogyakarta, Graha Ilmu

Artikel. Suara merdeka: Terapi kelompok untuk mengatasi stress. Dibuka dari

http//:www.Suaramerdeka.com/ha rian.

Artikel. Langkah Menghadapi Stres. Dibuka dari http//:Indomedia.com http://www.karawanginfo.com/?p=7636, Pemilukada Karawang : Antara Investasi Sosial, Investasi Politik Dan Investasi Ekonomi

Mage Ruslan Ismail: https://sitaro.wordpress.com/2012 /03/11/investasi-politikseharusnya-didasarkan-padainvestasi-sosial/ 